\title{
HIV Co-Infection with Hepatotropic Viruses and Mycobacterial Tuberculosis
}

\author{
Okeke $\mathrm{TC}^{1,2 *}$ and Anyaehie BU ${ }^{2}$ \\ ${ }^{1}$ Department of Obstetrics \& Gynaecology, University of Nigeria Teaching Hospital (UNTH), Enugu, Nigeria \\ ${ }^{2}$ Department of Physiology, University of Nigeria, College of Medicine, Unec, Enugu, Nigeria
}

\begin{abstract}
HIV Co-infection complicates the natural history, clinical course, therapy and management for HIV. The individuals affected represent a treatment challenge fraught with controversies associated with drug resistance, cross-resistance, hepatotoxicity and suboptimal response. This is a descriptive review of co-infection in HIV positive individuals. Studies have shown that HIV co-infection accelerates the natural course of hepatotropic viruses and increased risk of liver cirrhosis, hepatocellular carcinoma, and decompensated liver disease in co-infected individuals. Studies have equally shown increased risk of progression to acquired immunodeficiency syndrome AIDS and AIDS-related death among HIV/HCV co-infected persons and HCV may affect the management of HIV infection, increasing the incidence of liver toxicity associated with antiretroviral regimens. Dual HBV/ HCV co-infection tend to have more severe liver cirrhosis and hepatitis decompensation, and a higher incidence of hepatocellular carcinoma. HIV is a strong risk factor for TB. High prevalence rates are significantly correlated with high TB incidence rates. Tuberculosis equally accelerates the progression of disease in HIV.
\end{abstract}

Co-infection with HIV is a growing public health problem worldwide. There is need for enlightenment and further researches to highlight the importance of public health follow-up and reduction measures for HIV co-infected individuals in order to prevent subsequent infections.

Keywords: Co-infection; HIV; HBV; HCV; dual HBV/HCV; TB

\section{Introduction}

Co-infection is the simultaneous infection with two or more different disease causing organisms. Co-infections are common public health problems and recognized worldwide [1]. Co-infection with hepatitis viruses (hepatotropic viruses) are known to influence progression, management as well as outcome of HIV infection [1,2]. The viruses are blood borne pathogens and share similar routes of transmission [1,2]. It is a growing problem and is associated with increased risk of antiretroviral related hepatotoxicity and increased risk of progression to liver diseases which is a major cause of morbidity and mortality in HIV infected patients [3,4].

Co-infections in HIV positive individuals are seen with Hepatitis B Virus (HBV), Hepatitis C Virus (HCV), dual HBV and HCV, and Mycobacterium tuberculosis [5]. Worldwide, prevalence of co-infection among humans is unknown [6]. The prevalence is high worldwide, high prevalence of hepatotropic viruses in HIV positive individuals may be as a result of shared modes of transmission between HIV and hepatotropic virus infections, secondly, it may be due to the phenomenon of reactivation of hepatotropic viruses in the setting of HIV immunodeficiency, and lastly, sociodemographic factors: the unawareness of the population at large of the mode/route of transmission [7].

Co-infections and opportunistic infections are the major cause of deaths among HIV positive individuals due to risk factors, type of exposure and geographic region [8]. Co-infections are major burdens in the health care system in sub-Saharan Africa and Africa. Co-infection with hepatotropic viruses are characterized by a higher prevalence of injection drug use, poverty and psychiatric disorder [9]. Co-infection affects disease progression related to HIV and hepatitis viruses [10] and complicates treatment [11]. The rate of liver cirrhosis is up to six times higher in HIV co-infected persons than hepatitis viruses monoinfected $[12,13]$.
Co-infection of HIV with viruses have been recognized worldwide in individuals exposed to blood borne diseases, but limited data are available on the extent of co-infection, effect of these viruses on the immune system and liver in developing countries [7]. Nigeria is highly endemic for viral hepatitis. Few studies have been done on the prevalence of HIV/Hepatitis virus co-infection in Nigeria but the knowledge about the interrelationship between these viruses and their effect on the immune system remains unclear [7].

Clinical management and treatment of HIV co-infected patients is controversial, challenging and complex $[11,14]$. Abnormal hepatic function is one of the most common complications occurring among HIV infected individuals receiving antiretroviral therapy $[11,15]$.

It is well documented that all HIV co-infected individuals should be screened for $\mathrm{HCV}, \mathrm{HBV}$ and those with co-infection should be considered for anti HCV treatment [11,15-17]. However, treating HIV first is clearly indicated when CD4 lymphocyte count is very low $(<200$ cells $/ \mu \mathrm{L})[14]$.

\section{Methodology}

A systematic search of literature on co-infection with HIV published in English was conducted worldwide. Relevant materials on co-infection, HIV, HBV, HCV, dual HBV and HCV infections, HIV

*Corresponding author: Okeke TC, Department of Obstetrics \& Gynaecology, University of Nigeria Teaching Hospital UNTH, Enugu, Nigeria, E-mail: ubabiketochukwu@yahoo.com

Received June 30, 2013; Accepted July 29, 2013; Published August 03, 2013

Citation: Okeke TC, Anyaehie BU (2013) HIV Co-Infection with Hepatotropic Viruses and Mycobacterial Tuberculosis. J AIDS Clin Res 4: 229. doi: 10.4172/21556113.1000229

Copyright: ( 2013 Okeke TC, et al. This is an open-access article distributed under the terms of the Creative Commons Attribution License, which permits unrestricted use, distribution, and reproduction in any medium, provided the original author and source are credited. 
and TB were selected. Selected references, conference papers, technical reports, journal articles, abstracts, relevant books, lecture notes and internet articles using Medline, Google scholar and pubmed databases were critically reviewed.

\section{Organisms involved in Co-infection}

This review focused on HIV co-infection with HBV, HCV, HBV and HCV, and Mycobacterium tuberculosis.

\section{Human Immunodeficiency Virus (HIV)}

HIV is a retrovirus, a member of the lentivirinae sub family. The virus has a cylindrical nucleoid in the mature virion. HIV is the primary aetiologic agent of AIDS. HIV infects CD4 lymphocytes, causing their gradual depletion leading to immunosuppression. On average it takes 8-10 years from infection with HIV to the development of AIDS. Human AIDS viruses are not homogenous but most are variants of HIV-1. A second virus, HIV-2 is predominantly found in West African nations such as Guinea-Bissau, Burkina Faso, Gambia, Senegal, Cape Verde, Ivory Coast, Mali, Sierra Leone, and Nigeria. HIV-2 infection has also been reported in countries with historical and socioeconomic ties to West Africa. This is because HIV-2 may have spread from Guinea-Bissau to Portugal during the war of independence [18]. HIV-2 has also been reported in former Portuguese colonies such as Angola Mozambique and Brazil, and in parts of India with previous ties to Portugal such as Goa and Maharashtra [18]. In Portugal, HIV-2 is responsible for $4.5 \%$ of AIDS cases [19].

HIV-2 is much less virulent than HIV-1 because people infected with HIV-2 maintain higher CD4 T cell counts for longer periods of time and therefore take more time to progress to AIDS. About $40 \%$ of the sequences of HIV-1 and HIV-2 are identical [20]. Infection with HIV occurs through sexual contact, contact with infected blood. Risk factors are unprotected sexual intercourse with different partners and intravenous drug abuse. Measures to reduce HIV infection include education about HIV prevention and AIDS, promotion of condom use and effective diagnosis and treatment of other sexually transmitted diseases.

There are three approaches to HIV treatment [20]. These aim to

(a)Prevent replication of the virus

(b)Boost or strengthen the immune system

(c)Treatment of opportunistic infections

\section{Hepatitis B Virus (HBV)}

HBV belongs to the family Hepadnaviridae. It is blood borne hepatotropic double stranded DNA virus. It has three major structural antigens namely surface antigen ( $\mathrm{HbsAg}$ ), core antigen ( $\mathrm{HbcAg})$, and e antigen (HbeAg). HBV has a high infectivity. Clinical presentation when acquired in childhood may often be asymptomatic in up to $90 \%$ of individuals [21]. If acquired in adulthood as may be the case in intravenous drug abusers, the chances of having symptoms increases to $30 \%$ [22]. $80-95 \%$ of infants and young children with HBV become carriers and their serum remains positive for HBsAg [21]. Nonspecific symptoms and signs may be present [23]. It may present as acute or chronic hepatitis. Acute hepatitis B is usually self-limiting. Fulminant hepatic failure may be seen in about $1 \%$ of cases. Nonspecific haematological tests may be seen with biochemistry revealing elevated serum aminotransferase. Diagnosis is by the presence of $\mathrm{HbsAg}$. HbeAg shows active disease with viral shedding into blood stream. Antibodies to $c$ begin to appear in the serum when HbcAg begins to disappear.
The presence of the e antigen indicates a high infectivity period and the presence of e antibodies indicate low infectivity. Complete resolution of the disease is indicated by the disappearance of HbsAg and the appearance of surface antibodies. Surface antibodies suggest immunity either when obtained from resolution of infection or vaccination with $\mathrm{HbsAg}$. The burden caused by HBV is a growing public health problem causing about two billion infections worldwide [24].

\section{Hepatitis C Virus (HCV)}

$\mathrm{HCV}$ is a blood borne single stranded RNA genome of positive polarity that belongs to the family Flaviviridae [25]. As with HBV, this virus is transmitted sexually and parenterally. The main group of hepatitis $\mathrm{C}$ positive individuals is with the injection drug users. The clinical features are nonspecific. HCV infection is often diagnosed with vague symptoms or when patients present with abnormal alanine transferase levels. Cirrhosis develops in $20-40 \%$ of patients with up to $3 \%$ risk of development of hepatocellular carcinoma annually [26]. Antibodies to hepatitis $\mathrm{C}$ appear readily late in the course of infection but if clinical suspicion is high, patients serum should be tested for hepatitis C RNA to establish a diagnosis.

\section{Mycobacteruim tuberculosis}

Mycobacteruim tuberculosis is a rod-shaped obligate aerobic bacterium that does not form spores. They are "acid fast" bacilli. It is an important pathogen of humans. Mycobacterium tuberculosis is the causative organisms for tuberculosis. Tuberculosis (TB) is a growing problem worldwide because of neglect of TB programs and spread of HIV. TB is more of an opportunistic infection associated with HIV. In Africa and Asia, TB is one of the most important life-threatening opportunistic infections associated with HIV. The spread of HIV has contributed to the emergence of epidemic in several ways. Risk factors for infection are poor living conditions, poor nutrition and overcrowding. Susceptibility is more at extremes of age and if immunecompromised. HIV is a well known risk factor for TB. There are two major patterns of the disease namely primary tuberculosis which is often seen in children as initial infection. The initial focus of infection is a small subpleural granuloma with hilar lymph mode infection. This granuloma resolves in majority of the cases if there is no further spread of the infection. The second pattern, is secondary TB which is seen mostly in adults. This is a reactivation of the primary disease particularly if there is decline in the person's immunity. The symptoms are gradual in onset with fatigue, weakness, weight loss, fever, night sweats and chronic cough with purulent or blood stained sputum. The sputum is positive for acid-fast bacilli when stained with Ziehl-Nielsen and cultures grown.

Effective TB control requires a properly functioning health service with good management, diagnostic facilities, trained staff and regular drug supplies including reserve stocks. These will ensure proper detection, prompt and effective treatment of patients with active TB and careful follow-up of their contacts with tuberculin tests, X-rays, appropriate treatment, immunization with BCG and preventive chemotherapy. However, financing TB programs has not been a priority in developing countries. Increasing homelessness and poverty are also contributing factors.

\section{Route of transmission}

All the viruses involved in co-infection share a similar route of transmission. Transmission is commonly through bodily secretions (principally blood and its products), urine, semen, sweat, saliva and tears, use of contaminated needles, sexual contact, intravenous drug 
abuse and vertical transmission (mother to child through infected birth canal) $[21,26,27]$. The importance of awareness of the routes of transmission of hepatotropic viruses and HIV co-infection should be emphasized since it borders on sociodemographic factors especially the level of health education on prevention [26,27].

\section{HIV/HBV Co-infection}

HIV/HBV Coinfection is common due to shared routes of transmission. Factors affecting the prevalence of chronic HBV include age at the time of infection and mode of acquisition, which vary geographically. HIB/HBV coinfection rates are highest among men who have sex with men (MSM) and injection drug users. This is more common in USA but in Asia and sub-Saharan Africa where vertical and early childhood exposure are the most common modes of transmission respectively, and overall HBV prevalence is higher, the prevalence of $\mathrm{HBV}$ among HIV infected individuals also is higher at an estimated $20-30 \%[28,29]$. In arrears of low endemicity, such as North America, Australia and Europe, HIV/HBC co-infection is usually acquired in adulthood through sexual or percutaneous transmission. In areas of low endemicity, the prevalence of chronic co-infection is 5-7\% among HIV infected individuals [30]. In countries with intermediate and high $\mathrm{HBV}$ endemicity, the main routes of transmission of $\mathrm{HBV}$ are perinatal or in early childhood. In these countries, HIV/HBV co-infection rates are $10-20 \%[31]$.

$\mathrm{HBV}$ is a DNA virus that forms stable circular covalently closed DNA that can persist in the liver indefinitely. This, may result in HBV reactivation in individuals with evidence of past infection (core antibody positivity), particularly in the setting of severe immunocompromise, prolonged steroid use, or chemotherapy. There are 8 genotypes of HBV. Genotype G may be predictive of more severe fibrosis in HIV coinfected patients [32] and genotypes $\mathrm{C}$ and $\mathrm{D}$ may be more responsive to interferon [33].

The course of acute HBV may be modified in the presence of HIV infection, presenting with a lower incidence of jaundice and low rate of spontaneous clearance of HBV [34]. The course of chronic HBV and HIV co-infection will present with higher levels of HBV DNA and lower rates of clearance of the hepatitis Be antigen (HBeAg) [35]. $\mathrm{HIV}$ increases the risk of cirrhosis and end-stage liver disease in HBV coinfection [36]. In some studies, the risk of liver related mortality has been found to be 2-3 times higher in HIV/HBV co-infected patients than in HIV-mono-infected patients [37]. HIV co-infection with HBV is associated with more frequent flares of hepatic transaminases, which can occur with immune reconstitution inflammatory syndrome (IRIS) owing to ART, interruption of HIV/HBV treatment, or the development of resistance to HIV/HBV treatment. These can occur spontaneously [32].

There are conflicting reports from authors with respect to the impact of HBV on the disease course of HIV infection. Some studies showed an increased rate of HIV progression to AIDS [38] while others reported no change in the progression of HIV disease or survival [39].

\section{HIV/HCV Co-infection}

Co-infection with HIV and HCV is common due to shared routes of transmission. The reported prevalence of $\mathrm{HIV} / \mathrm{HCV}$ coinfection varies significantly among studies. HIV and HCV are both transmitted through parental, sexual and vertical exposure but differ in the transmission efficiencies of these routes [40]. The risk factors of the population under study directly influence the prevalence in that particular population. For example, in HIV-positive patients with a history of IVDU (intravenous drug users), the rate of HCV infection is 82-93\% [41], while sexual transmission of HCV is relatively inefficient, and the rate of co-infection among HIV infected patients with sexual risk factor is less than $10 \%$ [41]. Men who have sex with me do not seem to have an overall-increased risk for coinfection [41]. The overall burden of co-infection is estimated at 4 to 5 million people worldwide [40]. For transmission via IVDU, HIV infected patients exposed to HCV are less likely to clear the acute infection [42]. For HIV/ HCV co-infected individuals it is more likely to transmit HCV [43]. Percutaneous exposure of health care workers to blood from coinfected patients was also shown to increase the risk of acquiring HCV [40]. Sexual transmission of $\mathrm{HCV}$ is rare even to partners of co-infected patients [44].

Co-infection with HIV has a significant impact on the life cycle of $\mathrm{HCV}$ and on the natural history of HCV infection. There is increase in HCV RNA levels in serum of co-infected patients after HIV seroconversion [45]. Similar findings were reported for HCV RNA in the liver [45]. This effect is related to the acquired immune-deficiency or to a direct interaction between the viruses.

The major impact of HIV/HCV co-infection on the natural history of HCV is the acceleration of liver disease progression. Co-infection $s$ associated with a higher mortality than mono infection with either virus alone [46]. This liver-related mortality decreased following introduction of HAART (highly active antiretroviral therapy) [47]. Studies have shown that excessive consumption of alcohol appears to be a cofactor that increases mortality from liver disease in co-infected patients $[40,47]$. Most cases of liver associated mortality in co-infected patients are due to end-stage liver disease or hepato-cellular carcinomia [48].

\section{Triple infection (HBV/HCV/HIV)}

Triple infection with $\mathrm{HBV} / \mathrm{HCV} / \mathrm{HIV}$ is a complex clinical presentation due to the interaction of $\mathrm{HBV}$ and HVC, and the impact of HIV on the immune system [28]. Furthermore, majority of the patients with $\mathrm{HIV} / \mathrm{HCV}$ co-infection are infected with $\mathrm{HCV}$ genotype 1, decreasing their response to interferon therapy and thereby rendering treatment more difficult [49].

In addition, HCV/HIV co-infection has been shown to result in more severe liver disease and an increased risk of liver disease - related death [50]. It is important to mention, that no standard care exists for co-infected patients with triple viruses. Management of this condition must be individualized and coordinated with an HIV specialist. Infection of HIV must be controlled before treatment of viral hepatitis can be considered [28].

\section{HIV and Mycobacteruim tuberculosis co-infection}

Tuberculosis (TB) is a dangerous growing global epidemic with emergence of HIV/AIDS and multi-drug resistant strains of the Mycobacterium tuberculosis. There is an increase in the number of people infected with both HIV and TB worldwide. About half of TB patients in sub-Saharan Africa are also infected with HIV [51]. In Asia, TB is one of the most important life threatening opportunistic infections associated with HIV. In Europe and North America there has also been a rise in TB cases since mid-1980s [51]. The recent resurgence of TB with HIV pandemic remains a major public health dilemma with TB as the leading cause of death among persons with HIV/AIDS despite the use of highly active antiretroviral therapy (HAART) [52]. In 1993, World Health Organization (WHO) declared TB as a global emergency because of the rising cases of deaths and infection rates [53]. 
TB is a leading public health problem worldwide, but is most felt in the developing world.

HIV is the strongest known risk factor for TB. High HIV prevalence rates are significantly correlated with high TB incidence rates [54]. The higher case - fatality rate of TB in HIV co-infection may be as a result of the following factors associated with HIV infection.

(a)Rapid progression of disease due to the failure of immune responses to restrict the growth of mycobacterium $\mathrm{TB}$

(b)Delay in the diagnosis and treatment of TB infection due to atypical presentation and lower rates of sputum smear positivity [55].

(c)Delay in the diagnosis of HIV infection due to stigma or insufficient uptake of HIV testing in TB clinics [56].

(d) Lack of access to combination antiretroviral therapy (ART) [55].

(e) Higher rates of multi-drug resistance TB due to a delay in initiation of effective therapy [57].

Burden of deaths from HIV co-infected TB was highest in South Africa, West Africa and East Africa [56]. In developing countries, majority of people live in slums. Slum life is associated with crowded housing, poverty, poor ventilation, poor nutrition and lack of access to quality health care. All these are associated with TB transmission [58]. Some socioeconomic determinants of TB are also associated with risk of HIV transmission such as injection drug use and commercial sex work. TB accelerates the progression of disease in HIV [59].

\section{Pathogenesis of liver disease in HIV co-infection with hepatotropic viruses}

The mechanisms underlying accelerated liver disease in hepatotropic viruses/HIV co-infected individuals are poorly understood but may include the following: direct viral effects on hepatocytes and hepatic stellate cells, and immunologic alterations such as immune activation, apoptosis and diminished HCV specific Tcell reponses [60-63]. In addition, liver toxicity of antiretroviral drugs and the burden of metabolic disease may contribute to a faster progression of liver fibrosis in HIV/ HCV co-infection. HIV immune activation induces cytokine changes (e.g. IL -4 , IL -5 , and IL -13 , TGF $-\beta$ ) that increase liver inflammation and fibrosis $[60,62,63]$. Co-infection increases apoptosis of hepatocytes through a Fas/Fas L pathway that could account for accelerated liver disease [62,63]. Accumulation of cytotoxic CD8 T cells in the liver that increases inflammatory mediators in co-infected compared to $\mathrm{HCV}$ monoinfected patients may also lead to increased tissue damage in coinfected patients [60]. Recent evidence shows HIV specific CD8 Tcells accumulate in the liver in co-infection and produce TNF - $\infty$, which is associated with liver fibrosis $[63,64]$. Recently, HIV related microbial translocation that causes systematic activation has been linked with severity of HCV - related liver disease [65].

Studies have shown HIV replication in hepatocytes and hepatic stellate cells (HSC) [63,66]. HIV infection of activated HSC promotes collagen expression and secretion of proinflammatory cytokines [66]. Studies have also shown that HIV proteins induce hepatocytes to apoptosis and release of inflammatory chemokines and cytokines that promote fibrosis [63]. HIV and HCV co-infection may increase tumour necrosis factor related apoptosis - inducing ligand (TRAIL) - mediated apoptosis of hepatocytes $[62,63,67]$.

In chronic $\mathrm{HCV}$, insulin resistance is common and it appears to be critical in liver steatosis and liver disease progression. The actual mechanism of insulin resistance involved in liver disease among HCV
- infected patients is poorly understood and unclear. It is thought that hyperinsulinemia and hyperglycemia stimulate HSC, resulting in increased connective tissue growth factor and accumulation of extracellular matrix [68].

When there is persistent hepatotropic viremia, liver fibrosis is the consequence of chronic inflammation leading to the final distortion of hepatic architecture and impairment of liver microcirculation and cell functions. The main effect of chronic hepatotropic infection is the progression to cirrhosis. This may be clinically silent apart from nonspecific symptoms until severe complications develop [69].

Hepatotropic infection is the most common cause of cirrhosis and most common indication for liver transplantation in North and South America, Europe, Australia and Japan [69]. The risk of developing cirrhosis ranges from $5 \%$ to $25 \%$ over a period of $25-30$ years [69,70]. Studies have shown that environmental and host factors can increase the risk or accelerate natural course of hepatotropic viruses related disease. These factors are alcohol consumption, age at the time of infection, male gender, degree of inflammation and fibrosis. Others are immuno-suppression, obesity and insulin resistance $[69,70]$.

Liver cirrhosis is a major risk factor for the development of hepatocellular carcinoma (HCC) [69]. HCC is the most severe complication of chronic inflammatory liver diseases and it is the most frequent primary liver cancer. Worldwide, the most frequent causes of HCC are HBV (54\%), HCV (31\%) and alcoholic abuse (15\%) [72]. It is well documented that in Africa and Asia, a cofactor in the HBV carcinogenesis is caused by dietary exposure to aflatoxin B [69]. About $90 \%$ of HCC are associated with a known underlying risk factor [69]. Since it is possible to identify patients at high risk for developing HCC, surveillance programs aimed at early detection of neoplastic lesions could help to reduce disease-related mortality from co-infection $[69,73]$.

\section{HIV-related immunosuppression on $\mathrm{HBeAg}$ clearance}

HBV disease can reactivate in the setting of severe immunosuppression. Patients may revert from inactive carrier status or from a state of resolved HBV infection to immune active status especially in immunocompromised state. This reactivation may be as a result of medications, chemotherapy or advanced AIDS [74,75]. $\mathrm{HBeAg}$ clearance means HBeAg is lost and HBV DNA declines, often to undetectable levels. $\mathrm{HBe} A B$ seroconversion can occur, followed by $\mathrm{HBs} A B$ seroconversion, indicating immune control of $\mathrm{HBV}$ infection. A small proportion of people will continue to have detectable low-level HBV DNA, which may be intermittent and this condition is described as "occult HBV infection".

\section{The role of immunology in the pathogenesis of $\mathrm{HIV} / \mathrm{HBV}$ related liver disease}

HBV forms stable circular covalently closed DNA that can persist in the liver indefinitely. The increased liver-related mortality in HIV/ HBV co-infection is complex involving both viruses and the immune response to each virus. In the setting of severe immunocompromise, HIV infects multiple cells in the liver and might potentially alter the life cycle of HBV. Though there is limitation of evidence to back it up. There are unique mutations in HBV which is defined in HIV/ HBV-coinfected individuals and might directly alter pathogenesis. Furthermore, an impaired HBV- specific CD4+ or CD8+ T-cell immune response in the setting of HIV is likely to be important. Progression to cirrhosis seems to be more rapid and more common, and liver-related mortality is higher in HIV/HBV than with mono-infected virus. 


\section{Importance of co-infection}

The importance of co-infection shows that individuals at risk of HIV are concomitantly at risk of acquiring parenterally or sexually transmitted viruses, including HBV and HCV. The shared modes of transmission is common in endemic areas and among subjects with a high risk of parenteral infections [76,77].

Co-infection with HIV and hepatotropic viruses is a common growing public health problem [78]. Co-infection alters the natural history of each of these viruses in a peculiar way. Co-infected patients represent a diverse group with various viral replications and immunity profiles [28].Worldwide, prevalence of $\mathrm{HBV} / \mathrm{HCV}$ co-infection with $\mathrm{HIV}$ is unknown. It could not be accurately determined because of the phenomenon of silent HBV infection. HCV super infection in patients with chronic HBV infection is a common clinical observation in AsiaPacific Countries and Africa [71]. An important clinical observation is characterized by interference between the two viruses, which result in an inhibition of HBV replication exerted by HCV. Further studies have shown that the virological patterns in co-infection cases are widely divergent and dynamic profiles overtime [77].

Studies have shown that HIV co-infection accelerates the natural course of chronic hepatitis $\mathrm{C}$ and $\mathrm{B}$ viruses and increased risk of liver cirrhosis, hepatocellular carcinoma and decompensated liver disease has been found in co-infected individuals [76,77,79]. Other studies have shown an increased risk of progression to acquired immune-deficiency syndrome (AIDS) and AIDS-related death among HIV-HCV positive individuals. Thus, indicating that $\mathrm{HCV}$ co-infection may accelerate the course of HIV disease. Dual HBV/HCV co-infection tends to have more severe liver injury, enhanced liver cirrhosis and hepatic decompensation and a higher incidence of hepatocellular carcinoma.

A detailed serological, and virological evaluations are necessary and required for co-infected patients before initiation of antiviral therapy. Earlier studies demonstrated that $\mathrm{HBV} / \mathrm{HCV}$ co-infected patients responded poorly to interferon (IFN) monotherapy [80]. Recent studies have shown that co-infected patients with dual active $\mathrm{HBV} / \mathrm{HCV}$, the optimal regimen for therapy remains poorly understood and unclear [77].

$\mathrm{HCV} / \mathrm{HBV}$ co-infection may affect the management of HIV infection, increasing the incidence of liver toxicity associated with antiretroviral regimens. This is however, a treatment challenge. No standard recommendation exist for treatment of viral hepatitis due to dual HBV/HCV infection, and therefore, treatment must be individualized based on patient variables such as serologic and virologic profiles, patients prior exposure to antiviral treatment, and the presence of other parenterally transmitted viruses such as HIV.

There is uncertainity in the optimal therapeutic approach to HCV infection in HIV co-infected individuals. There is controversy in this management up till date, because of the complex pathogenesis of these infections, potential drug interactions, the poor literature and information available about safety and efficacy of an interferon and ribavirin combination in this group of patients [78]. Studies have shown that virological response rates in co-infected persons treated with standard interferon plus ribavirin range from $18-40 \%$ and several studies with pegylated interferon plus ribavirin are inconclusive and its outcome poorly understood [76].

After the introduction of highly active antiretroviral therapy (HAART) in the management of HIV, liver disease has emerged as a major cause of morbidity and mortality [76]. Treatment of HBV with HIV co-infection is complex and poorly understood because the drugs used are associated with drug-resistance, cross-resistance, hepatotoxicity and suboptimal response. Furthermore, management of patients not responding to standard therapy is not known [76].

\section{Prevention of co-infection}

HIV positive individuals should not share toothbrushes, razors or other personal items that may come in contact with an infected person's blood. People should endeavour to avoid tattoos from unlicensed facility or in an informal setting, which may use contaminated needles or contaminated instruments. People should ensure vaccination to prevent HBV, for those who have or are at risk for HIV infection, including MSM, people who inject drugs, sex partners of infected people, people with multiple sex partners, anyone with a sexually transmitted infection, and health care and public safety workers exposed to blood on the job. Currently, there is no vaccine for HCV. The best approach to HCV prevention is to stop injecting drugs if one has been on that habit. It is better to use new sterile syringes and never reuse or share syringes, needle or other drug preparation equipment. The risk could be reduced by abstaining from sexual intercourse, being monogamous, use of condom and being tested for sexually transmitted diseases and HIV.

In addition, identification, testing and counseling of at risk persons. To reduce the risk of new infections, donor screening, education and infection control practices to be encouraged. There should be regular medical evaluations, to monitor the disease trends and measure the effectiveness of prevention programs. Finally, since these hepatotropic viruses have similar mode of transmission with HIV, there is need to intensify risk reduction education programs such as safe sex program and other optimal models of integrated care so as to reduce the risk of viral transmission of HIV and hepatotropic viruses [2,7].

\section{Occupational Co-infection with $\mathrm{HBV} / \mathrm{HCV}$ and $\mathrm{HIV}$}

The first case of occupational HIV transmission was reported 29 years ago [81]. More than ten cases of co-infection among health care workers have been reported worldwide in the medical literature. When assessing the serostatus of source patients, it is important to remember that spontaneous disappearance of antibodies to HCV has been reported and that HCV seroreversion is two times more likely in HIV positive than in HIV negative patients [82]. The occupational co-infection with $\mathrm{HBV} / \mathrm{HCV}$ and HIV were as a result of sustained conjuctival exposure from blood splash, and oral mucosa exposure, percutaneous exposure, blood splashes or sprays, and needle stick injury [83]. Our greatest efforts should be focused on preventing occupational infections with HIV and HCV or co-infections with both, through the use of safetyengineered devices, personal protective equipment and safer work practices [83].

\section{Treatment of co-infection in HIV positive individuals}

The treatment of co-infection of hepatotropic viruses with HIV is fraught with a lot of controversies as to when to treat, which one to be treated first and whether treatment is required for HCV. However, a person with both HIV and HCV should be evaluated to determine the extent of liver disease, whether treatment is required for HCV and the safety of treating at a particular time. The only contraindication to HCV medications specific to HIV positive individuals is an active opportunistic infection.

HIV positive individuals can be successfully treated in people with hepatitis C. Some authors believe that it is better to begin HIV treatment 
first because HIV replication has to be controlled to allow for increase in the CD4 count, since HCV treatment works better in individuals with higher CD4 count with stronger immune system. Although, some authors are of the opinion that CD4 counts do not increase rapidly in co-infected individuals after starting HIV treatment as observed with HIV positive individuals alone. Management of co-infection should be individualized and may require a multi disciplinary approach (HIV specialist and a liver disease specialist and nurses specifically trained for HIV treatment). As a rule, the guidelines for treating HCV in HIV negative individuals can generally be applied to co-infected individuals as well since a lot of people with HCV do not require treatment. However, HIV positive individuals with $<20$ CD4 cells or a concurrent opportunistic illness are usually not considered good candidates for HCV treatment. Opportunistic illnesses should be treated first and HIV medications should be used to increase the $\mathrm{CD} 4$ count before treatment of HCV. Co-infected individuals with HCV and HIV should be treated with pegylated interferon plus ribavirin combination therapy. Coinfected people should be closely monitored during treatment. There is need for hospitalization and supportive care. Support groups are encouraged for co-infected individuals because of emotional challenges of living with these chronic life threatening diseases and stigma. These challenges are not impossible to overcome but do require that people have access to knowledgeable healthcare information and support in order to manage their dual conditions, live long and healthy lives. Coinfected individuals should avoid alcohol [84].

\section{Treatment of HIV/HBV coinfection}

The goal of HBV treatment for persons with HIV co-infection is to suppress HBV Viral replication and minimize ongoing hepatic damage. In HIV/HBV co-infection, indefinite treatment of HBV is often required because loss of HBsAg and seroconversion of $\mathrm{HBsAb}$ indicating resolution of active HBV disease are uncommon [85].

The drugs are controversial and likely to vary in different situations. Treatment recommendations include four main variables that should guide the selection of patients to be treated for HBV and of the drug of choice:

- Transaminase levels (ALT, AST)

- HBV DNA Viral loads

- HBV e-Antigen presence (HBeAg)

- Liver fibrosis staying (liver biopsy)

\section{- Ultrasound of the liver}

There is no evidence that HBV affects HIV disease progression or that HBV alters the response of HIV to antiretroviral therapy (ART). However, starting ART may be associated with an increased risk of liver inflammation in co-infected individuals, as evidenced by ALT (Alanine Amino Transferase) flares or rising liver enzymes. This may reflect both an immune response against HBV and /or drug toxicity. B namely

The following drugs are approved for treatment of chronic hepatitis

Interferon Alpha (Intron A) given by injection several times a week for 6 months to a year. Pegylated interferon (pegasys) given by injection once a week for six months to a year. Lamivudine is taken once a day for at least one year or longer. Adefovir Dipivoxil is a pill taken once a day for at least one year or longer. Entercavir is a pill taken once a day for at least one year or longer. Telbivudine is a pill taken once a day for at least one year or longer. Tenofovir is a pill taken once a day for at least one year or longer. Other drugs with anti HBV activity such as emtricitabine are FDA approved for treatment of HIV infection and are frequently used in coinfected patients as anti-HBV agents.

\section{Treatment of HIV/TB co-infection}

Patients with HIV/TB co-infection have greater risk of relapse raising concerns about the optimum duration of TB treatment $[86,87]$. WHO recommends that the standard 6 month therapy should be used for active TB in HIV positive patients. That, Intermittent 3-times weekly dosing schedules are acceptable alternatives to daily treatment in HIV-seropositive patients. WHO specifically recommends against using twice weekly dosing for HIV seropositive patients [88]. ART has been associated with marked reductions in the progression to AIDS and death [89]. Studies have shown that among HIV-infected persons rates of TB are significantly lower in those who receive ART and progressively decline with longer duration of ART [90].

\section{Issues in co-infection}

1. HCV is a flavivirus, which does not replicate through a DNA intermediate as retroviruses do. Unlike HIV, HCV does not integrate itself into human cells and therefore may be more easily eradicated. There is need for future research.

2. Both HIV and HCV are single-stranded RNA viruses with a high replication rate and high base misincorporation rate, which results in tremendous viral genetic diversity. This feature makes development of a vaccine quite problematic, since the ever expanding heterogeneity of viruses cannot be readily addressed with a single formulation, as had been accomplished with measles, polio, small pox and other successful vaccines.

3. As for the interaction between HCV and HBC, the mechanism of mutual inhibition is still unclear, especially for the suppression of HCV by HBV. Future research should be focused on these viral interactions.

4. There are no vaccines available for HIV and HCV but there is vaccine for HBV. Controversies exist in co-infection treatment because there is no standard of care available for treatment of patients with coinfection.

5. The latest treatment regimen, pegylated interferon plus ribavirin produce sustained viral clearance in many people with HCV alone. There is need for long-term maintenance therapy, as is done for HIV in an effort to reduce hepatitis $\mathrm{C}$ disease progression and prevent liver damage.

6. Regimens of multiple drugs that work by different mechanisms are more effective than monotherapy. This will prevent drug resistance and enhance eradication of the viruses.

\section{Conclusion}

Co-infection with HIV is a growing public health problem worldwide. There is need for enlightenment and further researches in order to highlight the importance of public health follow-up and reduction measures for HIV co-infected individuals in order to prevent subsequent infections.

\section{References}

1. Koziel MJ, Peters MG (2007) Viral hepatitis in HIV infection. N Engl J Med 356 1445-1454.

2. Kim JH, Psevdos G, Suh J, Sharp VL (2008) Co-infection of hepatitis B and hepatitis $C$ virus in human immunodeficiency virus-infected patients in New 
Citation: Okeke TC, Anyaehie BU (2013) HIV Co-Infection with Hepatotropic Viruses and Mycobacterial Tuberculosis. J AIDS Clin Res 4: 229. doi: $10.4172 / 2155-6113.1000229$

York City, United States. World J Gastroenterol 14: 6689-6693.

3. Sulkowski MS, Thomas DL, Chaisson RE, Moore RD (2000) Hepatotoxicity associated with antiretroviral therapy in adults infected with human immunodeficiency virus and the role of hepatitis $C$ or $B$ virus infection. JAMA 283: 74-80.

4. Weber R, Sabin CA, Friis-Møller N, Reiss P, El-Sadr WM, et al. (2006) Liverrelated deaths in persons infected with the human immunodeficiency virus: the D:A:D study. Arch Intern Med 166: 1632-1641.

5. Lawn SD (2004) AIDS in Africa: the impact of coinfections on the pathogenesis of HIV-1 infection. J Infect 48: 1-12.

6. Cox FE (2001) Concomitant infections, parasites and immune responses. Parasitology 122: S23-S38.

7. Okeke TC, Obi SN, Okezie OA, Ugwu EO, Akogu SP, et al. (2012) Coinfection with hepatitis $B$ and $C$ viruses among HIV positive pregnant women in Enugu south east, Nigeria. Niger J Med 21: 57-60.

8. Saha K, Firdaus R, Santra P, Pal J, Roy A, et al. (2011) Recent pattern of Coinfection amongst HIV seropositive individuals in tertiary care hospital, Kolkata. Virol J 8: 116.

9. Sulkowski MS, Thomas DL (2005) Perspectives on HIV/hepatitis C virus coinfection, illicit drug use and mental illness. AIDS 19 Suppl 3: S8-12.

10. Carter M (2004) HCV coinfection hastens HIV disease progression. IAPAC Mon 10: 433.

11. Lee W, Dieterich D (2004) Challenges in the management of HIV and hepatitis C virus co-infection. Drugs 64: 693-700.

12. Fuster D, Planas R, Muga R, Ballesteros AL, Santos J, et al. (2004) Advanced liver fibrosis in HIV/HCV-coinfected patients on antiretroviral therapy. AIDS Res Hum Retroviruses 20: 1293-1297.

13. Lesens O, Deschênes M, Steben M, Bélanger G, Tsoukas CM (1999) Hepatitis $C$ virus is related to progressive liver disease in human immunodeficiency virus-positive hemophiliacs and should be treated as an opportunistic infection. J Infect Dis 179: 1254-1258.

14. Côté P, Baril JG, Hébert MN, Klein M, Lalonde R, et al. (2007) Management and treatment of hepatitis $C$ virus in patients with HIV and hepatitis $C$ virus coinfection: A practical guide for health care professionals. Can J Infect Dis Med Microbiol 18: 293-303.

15. Romero M, Pérez-Olmeda M, García-Samaniego J, Soriano V (2004) Management of chronic hepatitis $C$ in patients co-infected with HIV: focus on safety considerations. Drug Saf 27: 7-24.

16. Soriano V, Garcìa-Samaniego J, Rodrìguez-Rosado R, Gonzàlez J, Pedreira J (1999) Hepatitis C and HIV infection: biological, clinical, and therapeutic implications. J Hepatol 31 Suppl 1: 119-123.

17. Cacoub P (2005) Treatment of hepatitis $C$ in HIV/hepatitis C co-infected patients: what is the evidence? Int J STD AIDS 16: 1-4.

18. de Silva TI, Cotten M, Rowland-Jones SL (2008) HIV-2: the forgotten AIDS virus. Trends Microbiol 16: 588-595.

19. Soriano V, Gomes P, Heneine W, Holguín A, Doruana M, et al. (2000) Human immunodeficiency virus type 2 (HIV-2) in Portugal: clinical spectrum, circulating subtypes, virus isolation, and plasma viral load. J Med Virol 61: 111-116.

20. Brooks GF, Caroll KC, Butel JS, Moorse SA (2007) Medical Microbiology. (24 Edn.), International Ed. Mac GrawHill Publishers, New York, 425-443.

21. Gillham JC (2010) Infection. In Luseley DM, Baker PN (Eds.), Obstetrics and Gynaecology: An evidence-based text for MRCOG. (1st Edn.), Arnold, London, 155-171.

22. Ryder SD, Beckingham IJ (2001) ABC of diseases of liver, pancreas, and biliary system: Acute hepatitis. BMJ 322: 151-153.

23. Tong S, Kim KH, Chante C, Wands J, Li J (2005) Hepatitis B Virus e Antigen Variants. Int J Med Sci 2: 2-7.

24. Takamizawa A, Mori C, Fuke I, Manabe S, Murakami S, et al. (1991) Structure and organization of the hepatitis $C$ virus genome isolated from human carriers. J Virol 65: 1105-1113.

25. Maddrey WC (2001) Update in hepatology. Ann Intern Med 134: 216-223.

26. Nwokedi EE, Emokpae MA, Dutse AI (2006) Human immunodeficiency virus and hepatitis B virus co-infection among patients in Kano Nigeria. Niger J Med
15: $227-229$.

27. Lesi OA, Kehinde MO, Oguh DN, Amira CO (2007) Hepatitis B and C virus infection in Nigerian patients with HIVIAIDS. Niger Postgrad Med J 14: 129 133.

28. Crockett SD, Keeffe EB (2005) Natural history and treatment of hepatitis B virus and hepatitis $C$ virus coinfection. Ann Clin Microbiol Antimicrob 4: 13.

29. Hoffmann CJ, Thio CL (2007) Clinical implications of HIV and hepatitis B coinfection in Asia and Africa. Lancet Infect Dis 7: 402-409.

30. Alter MJ (2006) Epidemiology of viral hepatitis and HIV co-infection. J Hepatol 44: S6-9.

31. Nyirenda M, Beadsworth MB, Stephany P, Hart CA, Hart IJ, et al. (2008) Prevalence of infection with hepatitis $B$ and $C$ virus and coinfection with HIV in medical inpatients in Malawi. J Infect 57: 72-77.

32. Lacombe K, Massari V, Girard PM, Serfaty L, Gozlan J, et al. (2006) Major role of hepatitis B genotypes in liver fibrosis during coinfection with HIV. AIDS 20: 419-427.

33. Akuta N, Kumada H (2005) Influence of hepatitis B virus genotypes on the response to antiviral therapies. J Antimicrob Chemother 55: 139-142.

34. Gatanaga H, Yasuoka A, Kikuchi Y, Tachikawa N, Oka S (2000) Influence of prior HIV-1 infection on the development of chronic hepatitis B infection. Eur J Clin Microbiol Infect Dis 19: 237-239.

35. Gilson RJ, Hawkins AE, Beecham MR, Ross E, Waite J, et al. (1997) Interactions between HIV and hepatitis B virus in homosexual men: effects on the natural history of infection. AIDS 11: 597-606.

36. Thio CL, Seaberg EC, Skolasky R Jr, Phair J, Visscher B, et al. (2002) HIV-1, hepatitis $B$ virus, and risk of liver-related mortality in the Multicenter Cohort Study (MACS). Lancet 360: 1921-1926.

37. Bonacini M, Louie S, Bzowej N, Wohl AR (2004) Survival in patients with HIV infection and viral hepatitis B or C: a cohort study. AIDS 18: 2039-2045.

38. Eskild A, Magnus P, Petersen G, Sohlberg C, Jensen F, et al. (1992) Hepatitis $B$ antibodies in HIV-infected homosexual men are associated with more rapid progression to AIDS. AIDS 6: 571-574.

39. Law WP, Duncombe CJ, Mahanontharit A, Boyd MA, Ruxrungtham K, et al (2004) Impact of viral hepatitis co-infection on response to antiretroviral therapy and HIV disease progression in the HIV-NAT cohort. AIDS 18: 1169-1177.

40. De Carli G, Puro V, Ippolito G; Studio Italiano Rischio Occupazionale da HIV Group (2003) Risk of hepatitis C virus transmission following percutaneous exposure in healthcare workers. Infection 31 Suppl 2: 22-27.

41. Mohsen AH, Murad S, Easterbrook PJ (2005) Prevalence of hepatitis $\mathrm{C}$ in an ethnically diverse HIV-1-infected cohort in south London. HIV Med 6: 206-215.

42. Bollepalli S, Mathieson K, Bay C, Hillier A, Post J, et al. (2007) Prevalence of risk factors for hepatitis $C$ virus in HIV-infected and HIV/hepatitis $C$ viruscoinfected patients. Sex Transm Dis 34: 367-370.

43. Polis CB, Shah SN, Johnson KE, Gupta A (2007) Impact of maternal HIV coinfection on the vertical transmission of hepatitis $C$ virus: a meta-analysis. Clin Infect Dis 44: 1123-1131.

44. Marincovich B, Castilla J, del Romero J, García S, Hernando V, et al (2003) Absence of hepatitis C virus transmission in a prospective cohort of heterosexual serodiscordant couples. Sex Transm Infect 79: 160-162.

45. Sherman KE, O'Brien J, Gutierrez AG, Harrison S, Urdea M, et al. (1993) Quantitative evaluation of hepatitis $C$ virus RNA in patients with concurrent human immunodeficiency virus infections. J Clin Microbiol 31: 2679-2682.

46. Arnold DM, Julian JA, Walker IR; Association of Hemophilia Clinic Directors of Canada (2006) Mortality rates and causes of death among all HIV-positive individuals with hemophilia in Canada over 21 years of follow-up. Blood 108: 460-464.

47. Rosenthal E, Pialoux G, Bernard N, Pradier C, Rey D, et al. (2007) Liver-related mortality in human-immunodeficiency-virus-infected patients between 1995 and 2003 in the French GERMIVIC Joint Study Group Network (MORTAVIC 2003 Study). J Viral Hepat 14: 183-188.

48. Salmon-Ceron D, Rosenthal E, Lewden C, Bouteloup V, May T, et al. (2009) Emerging role of hepatocellular carcinoma among liver-related causes of deaths in HIV-infected patients: The French national Mortalité 2005 study. J Hepatol 50: 736-745.

49. Rubio Caballero M, Rubio Rivas C, Nogués Biau A, Manonelles Fernández A 
Citation: Okeke TC, Anyaehie BU (2013) HIV Co-Infection with Hepatotropic Viruses and Mycobacterial Tuberculosis. J AIDS Clin Res 4: 229. doi: 10.4172/2155-6113.1000229

Page 8 of 8

(2005) [Epidemiology of chronic hepatitis $C$ virus in patients infected by human immunodeficiency virus. Study of 767 patients]. Med Clin (Barc) 125: 56-58.

50. Soriano V, Martín-Carbonero L, García-Samaniego J, Puoti M (2001) Mortality due to chronic viral liver disease among patients infected with human immunodeficiency virus. Clin Infect Dis 33: 1793-1795.

51. Olumide YM (2002) Clinical Presentation of HIVIAIDS. In: Olumide YM (Ed.), A self-instructional textbook of Acquired Immune Deficiency Syndrome (HIV/ AIDS) for Medical Students. Resident Doctors and Medical Practitioners, 2279.

52. Getahun H, Gunneberg C, Granich R, Nunn P (2010) HIV infection-associated tuberculosis: the epidemiology and the response. Clin Infect Dis 50 Suppl 3: S201-207.

53. Health Alert Asia Pacific 2003; $2: 1$

54. WHO (2009) Global TB control: a short update to the 2009 report. World Health Organization Geneva, Switzerland.

55. Cohen K, Meintjes G (2010) Management of individuals requiring antiretroviral therapy and TB treatment. Curr Opin HIV AIDS 5: 61-69.

56. WHO (2008) Essential Prevention and care interventions for adults and adolescents living with HIV in resource-limited settings. World Health Organization, Geneva, Switzerland.

57. Gandhi NR, Moll A, Sturm AW, Pawinski R, Govender T, et al. (2006) Extensively drug-resistant tuberculosis as a cause of death in patients co-infected with tuberculosis and HIV in a rural area of South Africa. Lancet 368: 1575-1580.

58. UNAID (2008) UNAIDS report on the global AIDS epidemic 2008. UNAIDS, Geneva, Switzerland.

59. Badri M, Ehrlich R, Wood R, Pulerwitz T, Maartens G (2001) Association between tuberculosis and HIV disease progression in a high tuberculosis prevalence area. Int J Tuberc Lung Dis 5: 225-232.

60. Operskalski EA, Kovacs A (2011) HIV/HCV co-infection: pathogenesis, clinical complications, treatment, and new therapeutic technologies. Curr HIVIAIDS Rep 8: 12-22.

61. Rotman Y, Liang TJ (2009) Coinfection with hepatitis C virus and human immunodeficiency virus: virological, immunological, and clinical outcomes. J Virol 83: 7366-7374.

62. Roe B, Hall WW (2008) Cellular and molecular interactions in coinfection with hepatitis $C$ virus and human immunodeficiency virus. Expert Rev Mol Med 10: e30.

63. Kim AY, Chung RT (2009) Coinfection with HIV-1 and HCV--a one-two punch. Gastroenterology 137: 795-814.

64. Vali B, Yue FY, Jones RB, Sheth PM, Kaul R, et al. (2008) HIV-specific T-cells accumulate in the liver in HCV/HIV co-infection. PLoS One 3: e3454

65. Balagopal A, Philp FH, Astemborski J, Block TM, Mehta A, et al. (2008) Human immunodeficiency virus-related microbial translocation and progression of hepatitis C. Gastroenterology 135: 226-233.

66. Blackard JT, Sherman KE (2008) HCV/ HIV co-infection: time to re-evaluate the role of HIV in the liver? J Viral Hepat 15: 323-330.

67. Nelson DR, Lau JYN (1998) Pathogenesis of chronic hepatitis C virus infection. Antivir Ther 3: 25-35.

68. Merchante N, Rivero A, de Los Santos-Gil I, Merino D, Márquez M, et al. (2009) Insulin resistance is associated with liver stiffness in HIV/HCV co-infected patients. Gut 58: 1654-1660.

69. Zaltron S, Spinetti A, Biasi L, Baiguera C, Castelli F (2012) Chronic HCV infection: epidemiological and clinical relevance. BMC Infect Dis 12 Suppl 2 S2.

70. Seeff LB (2002) Natural history of chronic hepatitis C. Hepatology 36: S35-S46.

71. Massard J, Ratziu V, Thabut D, Moussalli J, Lebray P, et al. (2006) Natura history and predictors of disease severity in chronic hepatitis C. J Hepatol 44: S19-24.

72. Llovet JM, Burroughs A, Bruix J (2003) Hepatocellular carcinoma. Lancet 362 1907-1917.

73. Lee JM, Trevisani F, Vilgrain V, Wald C (2011) Imaging diagnosis and staging of hepatocellular carcinoma. Liver Transpl 17 Suppl 2: S34-43.
74. Hoofnagle JH (2009) Reactivation of hepatitis B. Hepatology 49: S156-165.

75. Palmore TN, Shah NL, Loomba R, Borg BB, Lopatin U, et al. (2009) Reactivation of hepatitis $B$ with reappearance of hepatitis $B$ surface antigen after chemotherapy and immunosuppression. Clin Gastroenterol Hepatol 7: 1130-1137.

76. Kumar R, Singla V, Kacharya Sk (2008) Impact and management of hepatitis B and hepatitis C virus co-infection in HIV patients. Trop Gastroenterol 29: 136 147

77. Chu CJ, Lee SD (2008) Hepatitis B virus/hepatitis C virus coinfection epidemiology, clinical features, viral interactions and treatment. J Gastroenterol Hepatol 23: 512-520.

78. Verucchi G, Calza L, Manfredi R, Chiodo F (2004) Human Immunodeficiency virus and hepatitis $C$ virus coinfection: epidemiology, natural history, therapeutic options and clinical management. Infection 32: 33-46.

79. Benvegnù L, Fattovich G, Noventa F, Tremolada F, Chemello L, et al. (1994) Concurrent hepatitis $B$ and $C$ virus infection and risk of hepatocellular carcinoma in cirrhosis. A prospective study. Cancer 74: 2442-2448.

80. Kaklamani E, Trichopoulos D, Tzonou A, Zavitsanos X, Koumantaki Y, et al. (1991) Hepatitis B and C viruses and their interaction in the origin of hepatocellular carcinoma. JAMA 265: 1974-1976.

81. [No authors listed] (1984) Needlestick transmission of HTLV-III from a patien infected in Africa. Lancet 2: 1376-1377.

82. Ragni MV, Ndimbie OK, Rice EO, Bontempo FA, Nedjar S (1993) The presence of hepatitis $\mathrm{C}$ virus (HCV) antibody in human immunodeficiency virus-positive hemophilic men undergoing HCV "seroreversion". Blood 82: 1010-1015.

83. De Carli G, Perry J, Jagger J (2004) Occupational coinfection with HIV and HCV. Advances in exposure prevention 7: 13-17.

84. Fishbein DA, Lo Y, Netski D, Thomas DL, Klein RS (2006) Predictors of hepatitis $C$ virus RNA levels in a prospective cohort study of drug users. J Acquir Immune Defic Syndr 41: 471-476.

85. Lok AS, Heathcote EJ, Hoofnagle JH (2001) Management of hepatitis B 2000--summary of a workshop. Gastroenterology 120: 1828-1853.

86. Korenromp EL, Scano F, Williams BG, Dye C, Nunn P (2003) Effects of human immunodeficiency virus infection on recurrence of tuberculosis after rifampinbased treatment: an analytical review. Clin Infect Dis 37: 101-112.

87. Dlodlo RA, Fujiwara PI, Enarson DA (2005) Should tuberculosis treatment and control be addressed differently in HIV-infected and -uninfected individuals? Eur Respir J 25: 751-757.

88. WHO (2003) Treatment of tuberculosis: guidelines for national treatment programmes. ( $3^{\text {rd }}$ Edn), World Health Organization, Geneva.

89. Sterne JA, Hernán MA, Ledergerber B, Tilling K, Weber R, et al. (2005) Longterm effectiveness of potent antiretroviral therapy in preventing AIDS and death: a prospective cohort study. Lancet 366: 378-384.

90. Badri M, Wilson D, Wood R (2002) Effect of highly active antiretroviral therapy on incidence of tuberculosis in South Africa: a cohort study. Lancet 359: 2059 2064

This article was originally published in a special issue, Co-infections: HIV handled by Editor(s). Dr. Claudia Goulston, University of Utah, USA 